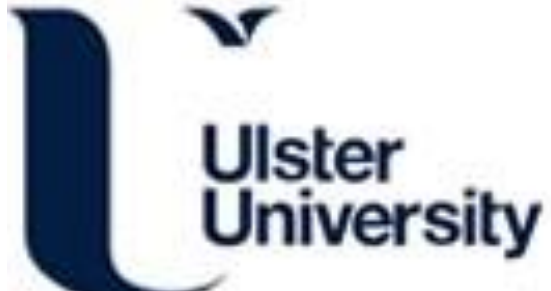

Evaluating the fabric performance and antibacterial properties of 3-D piezoelectric spacer fabric

Vatansever Bayramol, D., Soin, N., Dubey, A., Upadhyay, R. K., Priyadarshini, R., Roy, S. S., Shah, T. H., \& Anand, S. C. (2018). Evaluating the fabric performance and antibacterial properties of 3-D piezoelectric spacer fabric. Journal of the Textile Institute, 109(12), 1613-1619. https://doi.org/10.1080/00405000.2018.1437113

Link to publication record in Ulster University Research Portal

\section{Published in:}

Journal of the Textile Institute

Publication Status:

Published (in print/issue): 02/12/2018

DOI:

10.1080/00405000.2018.1437113

\section{Document Version}

Author Accepted version

\section{General rights}

Copyright for the publications made accessible via Ulster University's Research Portal is retained by the author(s) and / or other copyright owners and it is a condition of accessing these publications that users recognise and abide by the legal requirements associated with these rights.

\section{Take down policy}

The Research Portal is Ulster University's institutional repository that provides access to Ulster's research outputs. Every effort has been made to ensure that content in the Research Portal does not infringe any person's rights, or applicable UK laws. If you discover content in the Research Portal that you believe breaches copyright or violates any law, please contact pure-support@ulster.ac.uk. 


\section{Evaluating the fabric performance and anti-bacterial properties of 3-D piezoelectric spacer fabric}

Derman Vatansever Bayramol ${ }^{\mathrm{a}^{*}}$, Navneet Soin, ${ }^{\mathrm{b}^{*}}$ Amrita Dubey, ${ }^{\mathrm{c}}$ Ravi Kant Upadhyay, ${ }^{\mathrm{d}}$ Richa Priyadarshini, ${ }^{\mathrm{c}}$ Susanta Sinha Roy, ${ }^{\mathrm{d}}$ Tahir H. Shah ${ }^{\mathrm{b}}$ and Subhash C. Anand ${ }^{b}$

${ }^{a}$ Department of Textile Engineering, Namik Kemal University, 59860, Corlu-Tekirdag, Turkey ${ }^{b}$ Institute for Materials Research and Innovation, University of Bolton, BL3 5AB, United Kingdom

${ }^{c}$ Department of Life Sciences, School of Natural Sciences, Shiv Nadar University, Uttar Pradesh 201314, India

${ }^{d}$ Department of Physics, School of Natural Sciences, Shiv Nadar University, Uttar Pradesh 201314, India

*Corresponding authors:

Derman Vatansever Bayramol, Department of Textile Engineering, Namık Kemal University, 59860, Corlu-Tekirdag, Turkey. Email: dvbayramol@nku.edu.tr

Navneet Soin, Institute for Materials Research and Innovation, University of Bolton, BL3 5AB, United Kingdom. Email: n.soin@bolton.ac.uk 


\title{
Evaluating the fabric performance and anti-bacterial properties of 3-D piezoelectric spacer fabric
}

\begin{abstract}
The increasing need of on-demand power for enabling portable low-power devices and sensors has necessitated work in novel energy harvesting materials and devices. In a recent work (Soin et al., Energy Environ. Sci. 2014, 7(5), 1670), we demonstrated the production and suitability of 3-D spacer all fibre piezoelectric textiles for converting mechanical energy into electrical energy for wearable and technical applications. The current work investigates the textile performance properties of these 3-D piezoelectric fabrics including porosity, air permeability, water vapour transmission and bursting strength. Furthermore, as these textiles are intended for wearable applications, we have assessed their wear abrasion and consequently provide surface resistance measurements which can affect the lifetime and efficiency of charge collection in the piezoelectric textile structures. The results show that the novel smart fabric with a measured porosity of $68 \%$ had good air $\left(18551 / \mathrm{m}^{2} / \mathrm{s}\right)$ and water vapour permeability $\left(1.34 \mathrm{~g} / \mathrm{m}^{2} /\right.$ day $)$ values, good wear abrasion resistance over 60,000 rotations applied by a load of $12 \mathrm{kPa}$ and bursting strength higher than $2400 \mathrm{kPa}$. Moreover, the antibacterial activity of 3D piezoelectric fabrics revealed that owing to the use of Ag/PA66 yarns, the textiles exhibit excellent antibacterial activity against not only gram negative bacteria $E$. coli but they are also capable of killing antibiotic methicillin resistant bacteria S. aureus.
\end{abstract}

Keywords: piezoelectric, spacer fabric, properties

\section{Introduction}

Spacer fabrics are considered to be the next generation of technical textile structures which can be produced by weaving [1, 2, 3, 4], warp knitting [5, 6, 7], weft knitting [8, 9, 10, 11$]$ and nonwoven $[12,13]$ technologies. A spacer fabric consists of two outer layers, and a spacer layer of filaments (mono- or multi-) connecting the two outer layers to either join them together or to keep them apart. For knitted spacer fabrics, the outer layers consist of weft/warp knitted yarns which can be of the same or different materials. Due to the three-dimensional (3-D) structure, knitted spacer fabrics have found use in a number of applications including but not limited to vibration isolation [14], compression bandages [15, 16], prevention of chronic wounds [17, 18] and more recently in energy harvesting [19]. Using threedimensional knitted fabric as an energy generator for the conversion of mechanical energy of 
environment and human activities is one of the most recent area of research for 3-D fabric technologies. The first 3-D piezoelectric fabric, utilising the piezoelectric effect for the conversion of mechanical to electrical energy consisted of high $\beta$-phase $(\sim 80 \%)$ piezoelectric poly(vinylidene fluoride), PVDF monofilaments (300 dtex) as the spacer yarn interconnected between silver (Ag) coated polyamide multifilament yarn (143/34 dtex) and polyester (84 dtex) layers acting as the top and bottom electrodes [19]. The output power density of these 3$\mathrm{D}$ textiles were reported to be in the range of $1.10-5.10 \mu \mathrm{Wcm}^{-2}$, when subjected to an impact of 0.02-0.10 MPa, and is significantly higher than the existing 2D woven and nonwoven piezoelectric structures $[19,20,21]$. Such materials are generally named as "smart materials", with the ongoing research mostly focusing on enhancing their efficiency. However, for wearable energy harvesters, the thermophysiological properties of such structures are of equal importance and can potentially dictate their most appropriate application and further uptake as apparel or technical fabrics [22, 23].

One of the biggest advantages of 3-D spacer textiles is that the main layers can be manufactured from various yarns having different properties (conductive, anti-bacterial, heat resistant etc.), while the spacer monofilament can have entirely different property altogether. In the case of wearable spacer textiles, thermo-physiological comfort properties are highly desirable to facilitate the transport of the heat and moisture away from the skin and maintain the breathability of the fabric through sufficient air ventilation [24]. In the case of smart 3-D piezoelectric textiles intended for wearable and insole applications while creating and transferring the piezoelectric charge accounts for the power generation, a comfortable fabric which normalises the heat transfer during the mechanical impact by human body is simultaneously desired. For a multi-component textile structure as this, the repeated mechanical compression and impact required for charge generation will affect the fabric wear and lifetime. Apparel or technical fabric, it is very likely that they will undergo some mechanical impacts which will affect the fabric wear and lifetime. Therefore, wear resistance of the fabrics should be investigated together with comfort properties [25, 26]. For textile structures, either apparel or technical, their fabric performance is as much important as their underlying smart behaviour, such as piezoelectric behaviour in this case.

As compared to the traditional methods of textile production such as weaving, kitting, nonwovens; the 3-D spacer fabric production is a relatively new fabric production technique and as such there is only a limited amount of reported work on their fabric properties. Especially, the thermophysiological properties of smart technical textiles have not been reported before in the literature. In this work, we have measured the fabric performance 
parameters such as air permeability, wear abrasion, water vapour transmission and antibacterial of the 3-D energy harvesting piezoelectric fabrics. Additionally, we have also performed the surface resistance measurement of the fabrics at various stages of wear abrasion and observed the fraying nature of $\mathrm{Ag} / \mathrm{PA} 66$ fibres which can potentially affect the performance of the charge gathering capability. For smart textiles which can enable future wearable technologies, it is important to assess these fundamental properties in order to assess their suitability for long term use. Most of the recent research is now focused on the development of multifunctional smart materials which can exhibit multiple properties and functionalities. The 3-D spacer piezoelectric textile structure is a good example of such multifunctional smart textiles wherein it can be used complementarily in most places where an ordinary textile structures can be used and in terms of functionality it can generate an electrical charge upon an applied mechanical stimulus while also preventing the user from bacterial infections.

\section{Experimental procedure}

\section{Materials}

The 3-D piezoelectric fabrics were produced on an E20 circular weft knitting double-jersey machine at Baltex Speciality Knitters Ltd. Derbyshire, United Kingdom. A commercially available Ag coated PA66 conductive yarn (Shieldex, 143/34 dtex) was used in the knitted body together with an insulating polyester ( 84 dtex) yarn for plaiting. Piezoelectric PVDF monofilaments (300 dtex) were used as a spacer yarn between two knitted faces of the 3-D fabric structure (see Fig. 1). Further technical details of the PVDF yarn including the synthesis procedure alongside their crystalline, microstructural, piezoelectric properties can be found in our earlier work [19].

\section{Methods}

All fabric performance tests were carried out in laboratory conditions where the relative humidity and temperature are kept $65 \% \pm 2$ and $20^{\circ} \mathrm{C} \pm 2{ }^{\circ} \mathrm{C}$, respectively. Samples were kept in laboratory conditions for at least 24 hours before the tests. Fabric thickness of the 3-D piezoelectric knitted fabric was measured by a Karl Schröder KG thickness gauge which uses EN ISO 5084 standard. Mass per unit area $\left(\mathrm{g} / \mathrm{m}^{2}\right)$ of the fabric sample was measured by using precision scales. The bursting strength and bursting distension of the 3-D piezoelectric fabric was determined by using the hydraulic method which is based on the TS 393 EN ISO 13938-1 
test standard. The reported results are an average of triplicate measurements. For the investigation of the porosity of the piezoelectric spacer fabric, $20 \mathrm{~mm} \times 20 \mathrm{~mm}$ samples were prepared and weighted, with the measurements being done in triplicate. Toluene $\left(\mathrm{C}_{7} \mathrm{H}_{8}\right)$ with $99.5 \%$ purity and the density of $0.87-0.88 \mathrm{~g} / \mathrm{cm}^{3}$ was used to immerse the sample in wherein the idea is to use the toluene as a filler for the pores of the fabric. The samples were further weighed after the immersion process and the porosity of the complete fabric structure was calculated from the following equation [25]:

$$
P=\frac{\gamma_{r}-\gamma_{a}}{\gamma_{r}} * 100
$$

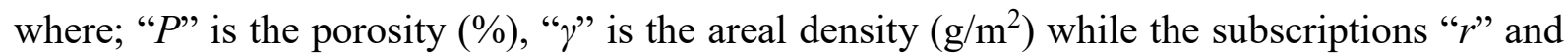
" $a$ " stand for relative and apparent, respectively. The air permeability characteristics of the 3D piezoelectric fabric were measured on PROWHITE ${ }^{\circledR}$ Airtest II equipment according to the EN ISO 9237 standard by using a $20 \mathrm{~cm}^{2}$ test head. For technical fabrics, the stipulated pressure is $200 \mathrm{~Pa}$ and accordingly 10 measurements were taken with the average value being reported. The water vapour transmission of the 3-D piezoelectric fabrics was investigated by using PROWHITE ${ }^{\circledR}$ water vapour permeability tester. The samples with a diameter of $96 \mathrm{~mm}$ were prepared as indicated in BS 7209 and the mass of the samples was recorded before the test. The as-prepared samples were covered and fixed on the receptacles $(83 \mathrm{~mm}$ inner diameter) containing $46 \mathrm{ml}$ of distilled water. Each sample set up was weighed and located on the rotating platform which rotated for 1 hour with a speed of $2 \mathrm{rpm}$ before the beginning of the actual test. This period is the time for transient behaviour of the fabric prior to reaching equilibrium. Each set up was weighed and put back onto the platform for next 24 hours to rotate with the same rotational speed. The test was carried out for 96 hours by weighing the samples after $24^{\text {th }}, 48^{\text {th }}, 72^{\text {th }}$ and $96^{\text {th }}$ hours. After 96 hours, the samples were taken off from the sample holder and weighed. The measurements were carried out in triplicate to ensure repeatability of the results. The water vapour transmission rate (WVTR) itself was calculated from the following equation [27]:

$$
W V T R=\frac{G}{t . A}
$$

where; " $G$ " is the weight change in grams, " $t$ " is the elapsed time in hours and " $A$ " is the test area (inner diameter of the water receptacle, in $\mathrm{m}^{2}$ ).

Textile materials undergo a number of friction/rubs during their everyday use during which they can get worn out resulting in damage and a consequential loss in the performance. It should be mentioned that majority of the wear abrasion occurs as a result of the fabricfabric friction. The wear abrasion test of the 3-D fabric was carried out by using a Martindale 
M235 abrasion and pilling tester. 3-D fabric samples were prepared as directed in ASTM D4966. The samples were rubbed against an abradant fabric with an applied weight of $12 \mathrm{kPa}$ and at a speed of $47.5 \mathrm{rpm}$. The samples with a diameter of $38 \mathrm{~mm}$ were weighed via precision scales before and after the rubbing cycles. The samples were rubbed 60,000 times in total. After each thousand rubs, the samples were taken out, weighed and inserted back.

The surface resistance of the 3-D fabric samples was also estimated by using the fourprobe method, adapted to textiles, by using cylindrical tips instead of point-contact tips [28]. During the measurement, a constant DC current, $I$, is passed through the two outer electrodes while measuring the potential drop, $U$, occurring between the two-middle electrodes. The surface resistance, $R_{S}$ is itself given by the following equation:

$$
R_{S}=\frac{\pi \cdot U}{\ln 2 . I}
$$

where $R_{s}$ is surface resistance $(V / s q$.$) , I is current (A)$, and $U$ is voltage $(V)$.

The electrical characteristics of the produced 3-D fabrics have been measured by a four-point probe system from "Everbeing Intl Corp" using a four-point probe head with a probe spacing of $1.5 \mathrm{~mm}$. The diameter of the Tungsten Carbide electrode contact tip was 0.4 $\mathrm{mm}$. The station was combined with a "Keithley 2450 " source meter for measuring the sheet resistance of the produced samples. The resistance measurements were carried out for samples before, during and after the abrasion tests.

For assessing the antibacterial properties of these textiles, two strains of bacteria, namely Gram-negative Escherichia coli (E.coli) MG1665 and Gram-positive Staphylococcus aureus (S.aureus) UAMS-1 have been used in the study. The E.coli cells were grown in Luria bertani (LB) broth (Hi-Media, Mumbai, India) at $37^{\circ} \mathrm{C}$ for $24 \mathrm{hrs.} \mathrm{S}$. aureus were cultivated in tryptic soy broth (TSB) and (TSA) agar (Hi-Media, Mumbai, India). Cells were harvested, centrifuged at $6000 \mathrm{rpm}$ for 5 minutes and washed with sterile phosphate buffer saline (PBS) solution. Bacterial cell suspensions were then re-suspended in PBS and diluted to obtain cell samples containing $\sim 10^{7}-10^{8} \mathrm{CFU} / \mathrm{ml}$ which were used for further experiments. To determine the antibacterial activity against E.coli and S.aureus, $1 \mathrm{~cm} \times 1 \mathrm{~cm}$ samples of the 3-D piezoelectric fabrics were used. Briefly, single swatches of fabric were dipped in bacterial cell suspensions and kept at $200 \mathrm{rpm}$ to ensure proper contact. Parallel experiments were also conducted with bacterial cell suspensions without any 3-D piezoelectric fabrics to use as positive control. After $3 \mathrm{hrs}, 100 \mu \mathrm{l}$ of the cell suspension was 10 fold serially diluted and spotted on agar plates. Simultaneously, $100 \mu 1$ of $10^{5}$ dilution was taken and spread on agar plates. 


\section{Results and Discussions}

The cross-section scanning electron microscope image of the 3-D piezoelectric fabric sample is shown in Fig. 1(b) which clearly shows the position of various fibres in the structure. Now, as compared to the conventional 2-D fabric structures, the 3-D fabrics can be considered as a relatively bulky structure, which was confirmed by the measured thickness of $\sim 3.51 \mathrm{~mm}$ with a mass per unit area of $485 \mathrm{~g} / \mathrm{m}^{2}$. As such, these materials may be more amenable for technical applications as compared to apparel. However, the fabric may still need to be in contact or closely located to the human body in applications such as shoe insole. Again, for such applications, the comfort properties of 3-D fabrics are as important as the functionally. The porosity of the spacer fabric itself is dictated by factors such as loop length, stitch density, thickness and structure of the fabric and consequently controls the permeability and thermophysiological properties [26]. For the 3-D piezoelectric spacer textile, the porosity, as evaluated by using Eq. 1 was determined to be $68 \pm 1 \%$. For an all-polyester warp-knitted 3-D spacer fabric of $3.1 \mathrm{~mm}$ thickness and an areal density of $491 \mathrm{~g} / \mathrm{m}^{2}$, a porosity value of nearly $88 \%$ was reported by Rajan et al. [26]. The air permeability of a fabric depends on structural factors such as surface finish of fabric, stitch density, thickness and type of spacer yarns while macroscopically, the number and size of pores affect the airflow through the structure. Now, if a fabric displays high porosity, it can be safely assumed that it is highly permeable. In our case, as the 3-D piezoelectric fabric structure is composed of two knitted layers of multifilament yarns with a spacer in between them, high air permeability values are expected. Consequently, the air permeability measurements for the 3-D piezoelectric fabric samples (carried out 10 times) revealed an average value of $18551 / \mathrm{m}^{2} / \mathrm{s}$. Comparatively, in their recent work, Arumugam et al. [29] have reported a value of nearly $9501 / \mathrm{s} / \mathrm{m}^{2}$ for 3-D all-polyester spacer fabric. As compared to the conventional 2-D fabrics, the 3-D fabrics are more breathable and hence show higher air permeability. The high porosity of the structure contributing to the high permeability value is clearly visible in the SEM images provided in Fig. 1. The high permeability has a subsequent significant impact on the ensuing comfort properties by allowing for the heat and water transfer to occur through the fabric thereby keeping the body cool.

The water vapour transfer characteristic of a textile material is an important parameter since it is directly related to the capability of the perspiration transfer. Therefore, textiles such as sport wears or shoe insoles are expected to have good water vapour transfer characteristic. The 3-D piezoelectric fabric test samples were prepared as indicated in BS7209 and then 
placed on the receptacles containing distilled water for evaluation of water vapour transmission. As mentioned earlier, the samples were weighed before and after each experiment wherein no significant change in the mass was observed. Therefore, it can be inferred that the water vapour was transmitted across directly without being engaged by the fabric, which can be attributed to the use of synthetic fibres, such as polyester, in the structure. Especially, the spacer yarn PVDF is highly hydrophobic and as such will not allow for any moisture uptake. As compared to the natural fibres, polyamide can readily uptake water, however, the silver coating on the PA66 fibres can potentially hinder the water uptake. As the 3-D fabric samples were kept in standard laboratory conditions $\left(20^{\circ} \mathrm{C} \pm 2\right.$ and $65 \% \pm 2 \%$ humidity) for 48 hours before the tests, it can also be argued that the water uptake of the polyamide had already reached the equilibrium before the test itself. The mass of the test assembly was measured at the beginning of the test as well as after 24-hour periods, with the result being shown in Fig. 3. Graph given in Figure 3, presents the decrease in total mass related to elapsed time i.e. the decrease in the mass of the test assembly provides information on how much water vapour is transmitted through the fabric in 24, 48, 72 and 96 hours. The amount of the water vapour transmitted through the fabric increases with the increase in time with the calculated transmitted water vapour value (Eq. 2) of $1.34 \mathrm{~g} / \mathrm{m}^{2} /$ day.

The bursting strength measurement of the 3-D fabric samples was carried out according to TS 393 EN ISO 13938-1 standard. Measurements in triplicate showed that a pressure higher than $2400 \mathrm{kPa}$ is needed before the fabric bursts. This value is remarkably high as compared to 2-D knitted fabric structures. Bursting strength of eleven 2-D knitted sportech fabrics were reported in the literature and they were found to be between $\sim 390 \mathrm{kPa}$ and $\sim 580 \mathrm{kPa}$ in the literature [30]. The wear abrasion performance of the piezoelectric fabrics was investigated by rubbing the fabric samples onto the abradant fabric at an applied weight of $12 \mathrm{kPa}$. Even though the plaiting of the yarns was done in exactly the same manner for both the faces, there was a slight visual difference in the two technical faces of the fabric. A "yellow" tone was dominant at one side while a "grey" tone was dominant at the other side and therefore, the wear abrasion tests was carried out for both the sides. Visuals of the samples after each ten-thousand rubs are given in Fig. 3(a-1). Small pilings were detected after 18,000 rubs, with an increase observed in their size and number with an increase in the rubbing cycles. However, no broken yarns or holes were observed for up to 60,000 rubs as seen in the Fig. 2(a-1). The wear abrasion of a textile structure can also be explained by the change in weight after wear abrasion test (Fig. 3(m)). After 60,000 rubs, the sample whose grey toned side was subjected to friction lost about $3 \mathrm{mg}$ of its weight, while the yellow toned 
side sample lost $2 \mathrm{mg}$ of its weight. However, there was not any visible yarn breakage or hole in the fabric. Since the used materials in presented 3-D piezoelectric spacer fabric were synthetic textile yarns and filaments, pile loss is not expected and could be attributed to the potential loss of Ag from Ag/PA66 yarns. To this effect, we have measured the surface resistance of the pristine technical faces of the fabric as well as at regular intervals during the rubbing cycles. As seen from Fig. 3(n), there is a systematic increase in the surface resistance of the abraded fabric samples which can only occur due to the loss of Ag from the Ag/PA66 yarns. With the increased number of friction cycles, fibrillation/fraying of the Ag/PA66 fibres was observed (see Fig. 4(d, h)) which can potentially cause the removal of loose fibres and consequentially an increase in the surface resistance.

The antibacterial activity of 3-D piezoelectric fabrics was examined against E.coli and S.aureus (Figure 5). E.coli and S.aureus cells were exposed to 3-D piezoelectric fabric in PBS solution for 3 hrs. Cell viability was determined by spot assay (Fig. 5 (a, b)) dilution and spread plate method (Fig. 5 (c)) discussed earlier in the experimental section. 3-D piezoelectric fabrics were found to be more potent against E.coli as we could not find any colony in any of the dilution factor Figure 5(a), also no growth was observed on the spread plate Figure 5(c). In contrast, control experiments performed in the absence of 3-D piezoelectric fabrics showed growth in all the dilutions (Fig. 5a). However, in case of $S$. aureus, the antibacterial efficacy of 3-D piezoelectric fabric was found to be reduced in comparison to E. coli. As shown in Figure 5(b), colonies were present at lower dilution whereas on increasing the dilution no colony formation was observed in $S$. aureus cells treated with 3-D piezoelectric fabrics. In case of untreated (control) $S$. aureus cells growth was observed in all the dilutions in spot assay. We can also conclude that at higher cell number (i.e. at lower dilution) colonies were present, however, at lower cell number (i.e. at higher dilution) no growth was observed as corroborated by our spot assay result in Figure $5 \mathrm{~b}$. Thus, confirming the antibacterial activity of 3-D piezoelectric fabrics.

The results revealed that silver coated 3-D piezoelectric fabrics exhibit antibacterial activity against not only Gram-negative bacteria E. coli but it is also capable of killing antibiotic methicillin resistant bacteria $S$. aureus [31]. The 3-D silver-coated fabric is found to be less potent as antibacterial against Gram-positive bacteria $S$. aureus, as compared to the Gram-negative bacteria E. coli; this observation is in well agreement with several previously published reports. Previously, several studies have reported better antibacterial activity of the silver nanoparticles against Gram-negative bacteria, as compared to the Gram-positive bacteria $S$. aureus $[32,33,34,35]$. The reason behind better bacteriocidal activity of the $\mathrm{Ag}$ 
against $S$. aureus compare to the $E$. coli is believed to be because of the complex cell membrane structure of the $S$. aureus compare to E. coli. The S. aureus contains thick lipoteichoic acid containing peptidoglycan layer and cell membrane as compared to the E. coli [32]. The thickness of the peptidoglycan layer for S. aureus and E. coli is estimated to be in the range of 20-80 $\mathrm{nm}$ and 7-8 $\mathrm{nm}$, respectively. The thicker peptidoglycan layer of the $S$. aureus provides it better protection compare to the E. coli against the attack of the reactive oxygen species (ROS) generated by the silver. Thus, the 3-D fabric samples are highly effective in stopping the growth and propagation of both the Gram-positive and Gramnegative bacteria and as such could be used for fabrication of smart functional textiles with antibacterial properties.

\section{Conclusions}

The as-prepared 3-D knitted piezoelectric spacer fabric was tested for its fabric performances and antibacterial properties. The thickness, mass and porosity of the fabric were measured and found to be $3.51 \mathrm{~mm}, 485 \mathrm{~g} / \mathrm{m}^{2}$ and $68 \%$, respectively. Both the air permeability and water vapour transmission test results revealed that 3-D knitted piezoelectric spacer fabric is both air and water vapour permeable owing to its porous structure. The resistance to wear abrasion test results showed that the fabric could easily endure over 60000 rubs, applied at $12 \mathrm{kPa}$ with a high bursting strength of more than $2400 \mathrm{kPa}$. Furthermore, the antibacterial activity of 3-D piezoelectric fabrics was examined against E.coli and S.aureus with the results showing that the 3-D piezoelectric fabric was more efficient against E.coli in comparison to S.aureus. The tests conducted during the course of the work reveal that the newly introduced multifunctional 3-D knitted piezoelectric spacer fabric has good fabric performance features for providing long term durability for enabling technical applications such as wearable energy harvesters with inherent antibacterial properties.

\section{Acknowledgements:}

The authors would like to thank Dr Erhan Sancak and Dr Mustafa Sabri Ozen at the Department of Textile Engineering, Faculty of Technology, Marmara University, Istanbul, Turkey for their help in electrical measurements. 

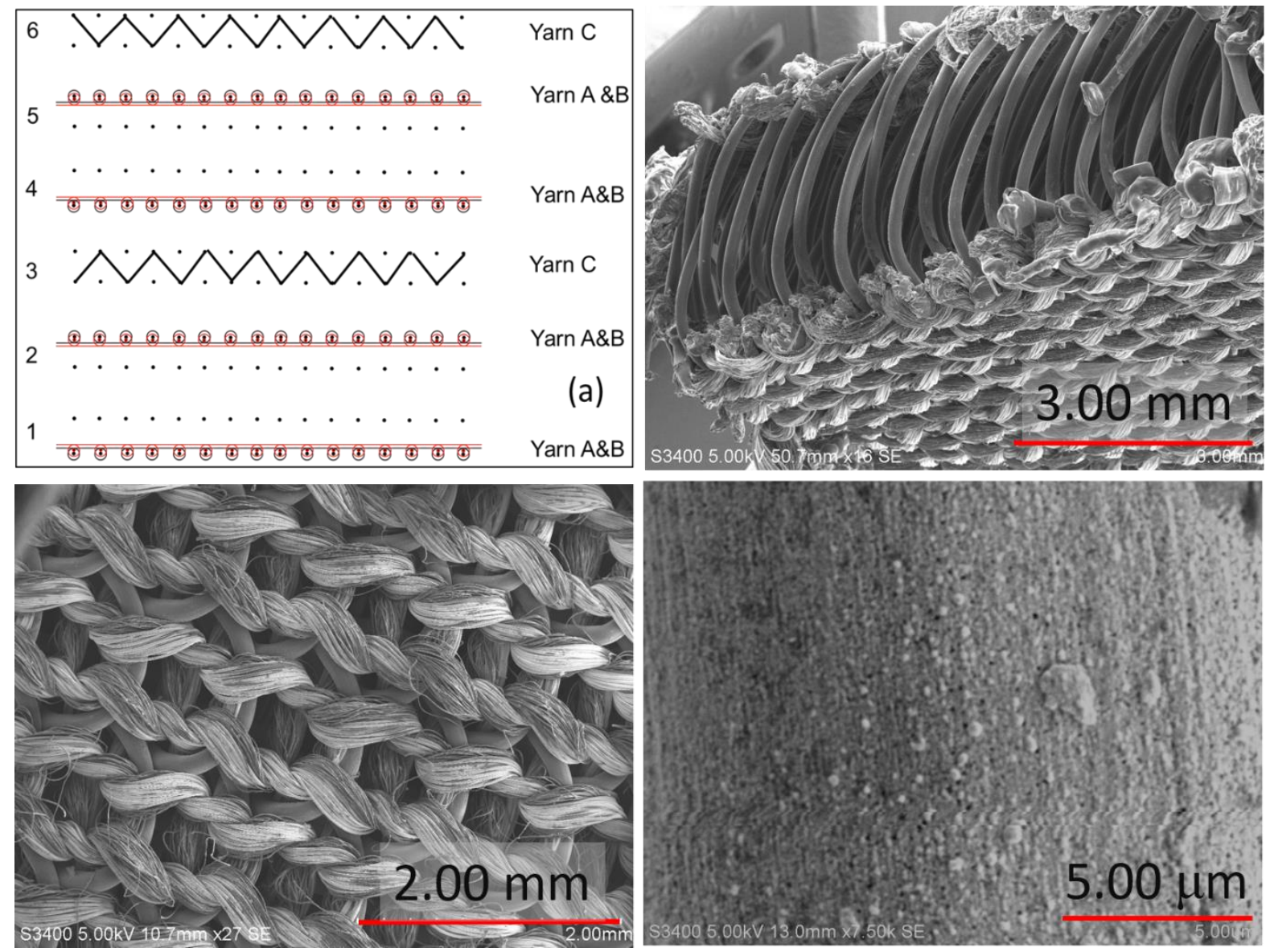

Fig. 1: (a) Schematic of fabric structure with the position of various yarns in the structure, yarn $\mathrm{C}$ is the PVDF spacer whereas yarns $\mathrm{A}$ and $\mathrm{B}$ correspond to the $\mathrm{Ag} / \mathrm{PA} 66$ and polyester plaiting yarns, (b) cross-sectional SEM image of the actual fabric clearly showing the position of piezoelectric and conductive yarns, (c) technical face of the fabric and (d) electroplated Ag on the Ag/PA66 yarns. 


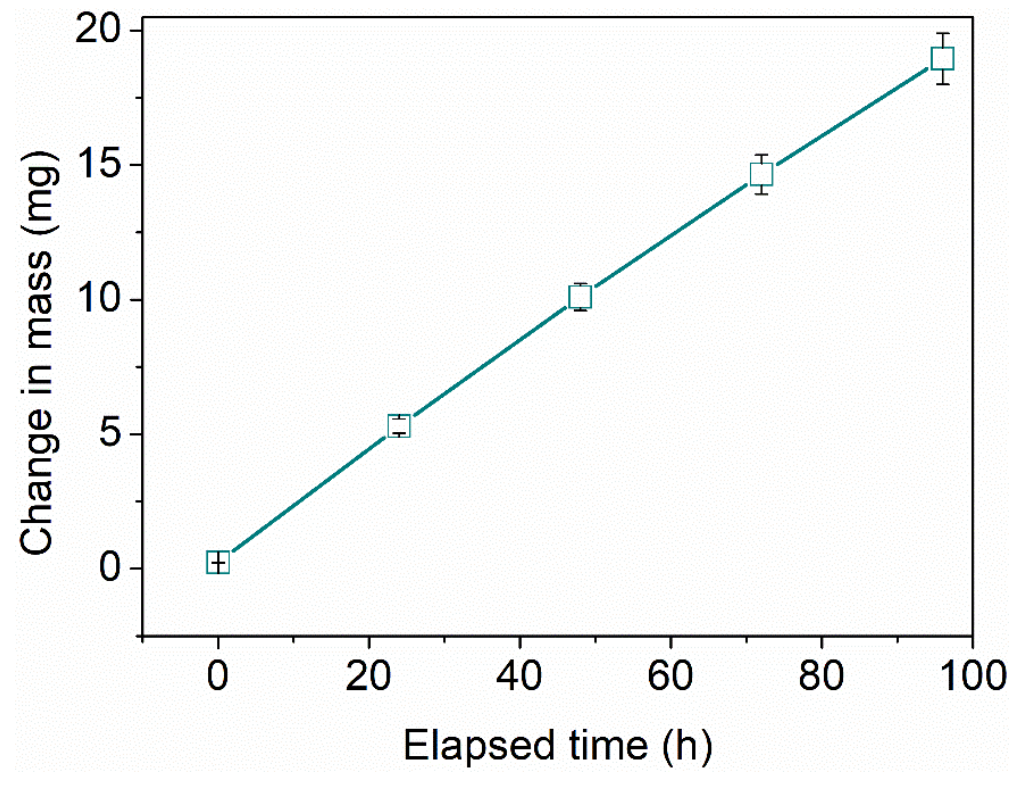

Fig. 2. Total mass change $(\mathrm{mg})$ of the test assembly, prepared for water vapour permeability test, measured after $0,24,48,72$ and 96 hours. 

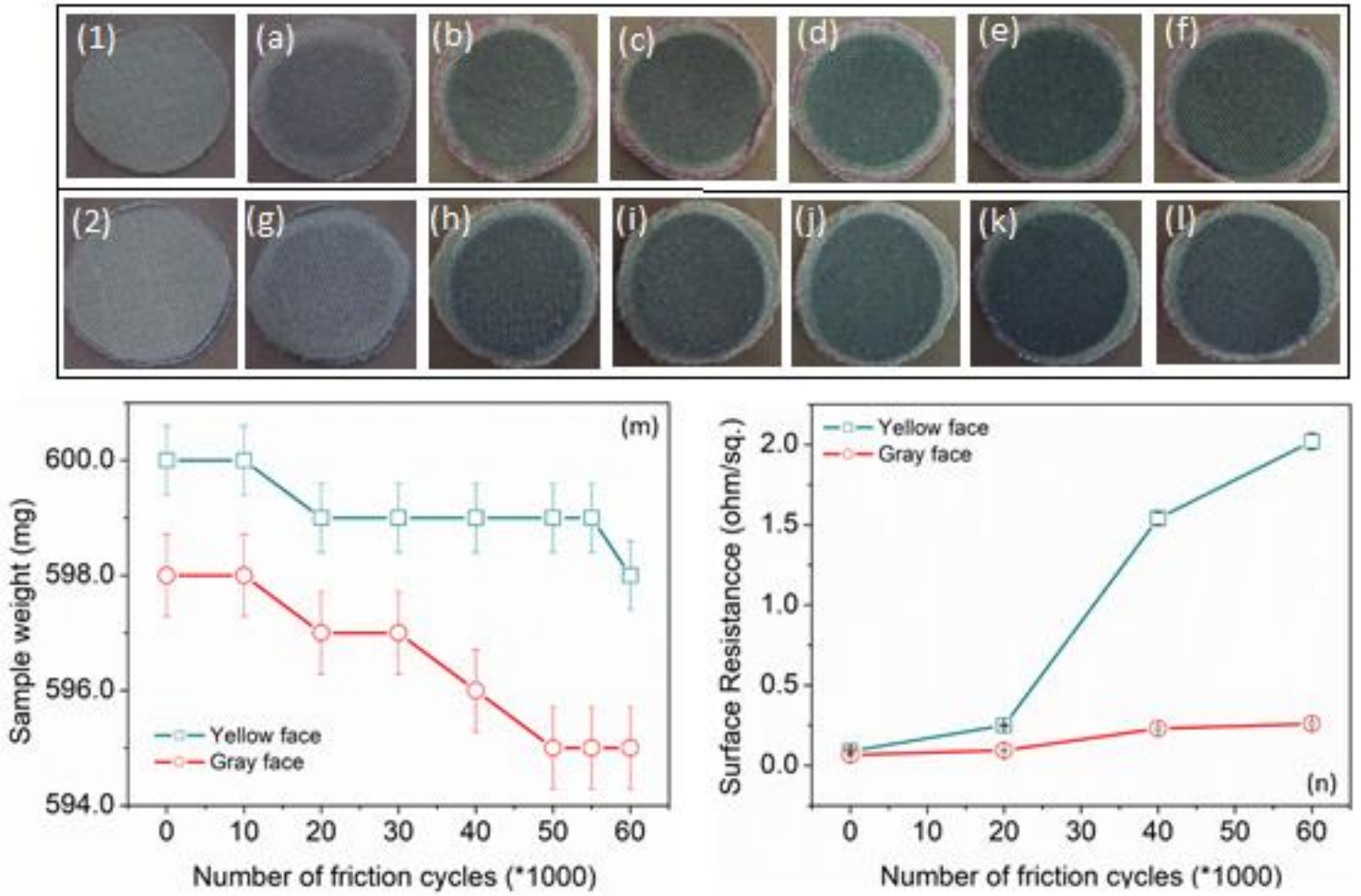

Fig. 3: Digital photographs of the 3-D piezoelectric fabrics taken before the wear test (1\&2) and after each $10,000$ rubs for the (a-f) yellow face and ( $\mathrm{g}-\mathrm{l})$ grey face, under an applied weight of $12 \mathrm{kPa}$. The corresponding change in the (m) weight and (n) sheet resistance of the two fabric faces as a function of number of friction cycles. 

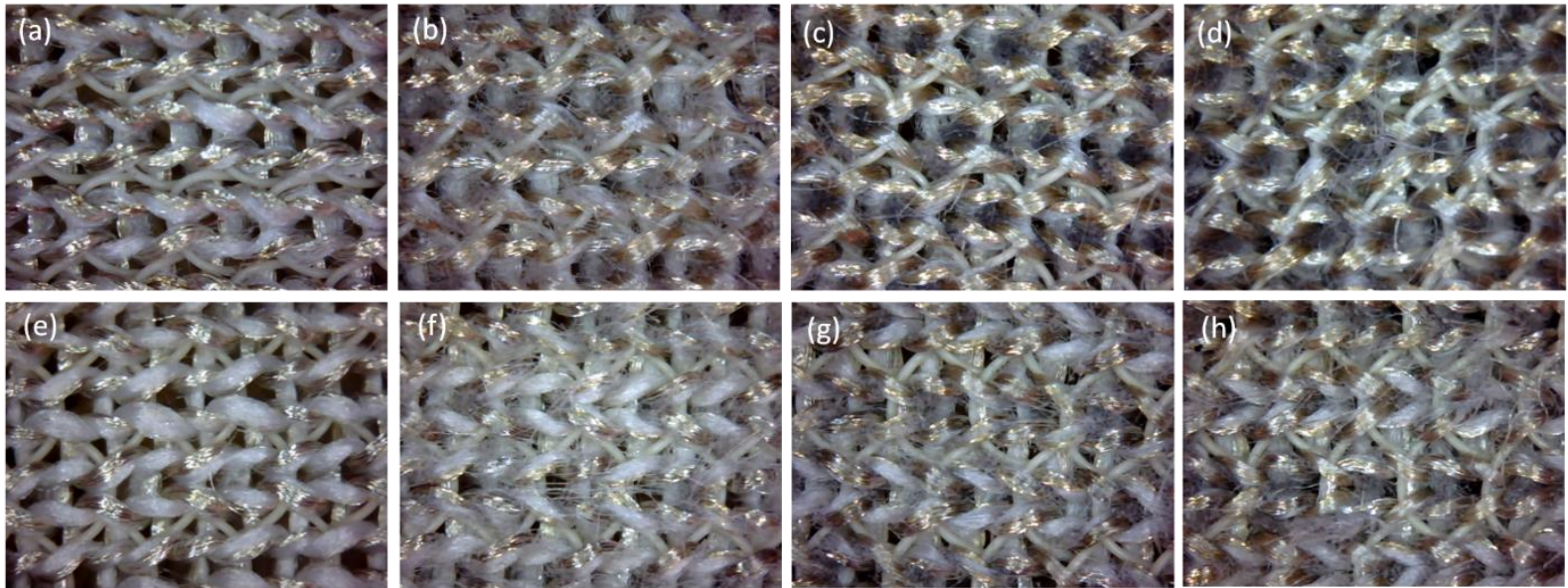

Fig. 4: Digital photographs of the (a-d) yellow face and (e-h) grey face of the 3-D piezoelectric fabrics. (a) and (e) were taken before the test (unrubbed samples) while (b-d) and (f-h) were taken after each 20,000 rubs showing the fraying of the $\mathrm{Ag} / \mathrm{PA} 66$ fibres after rubbing tests. 


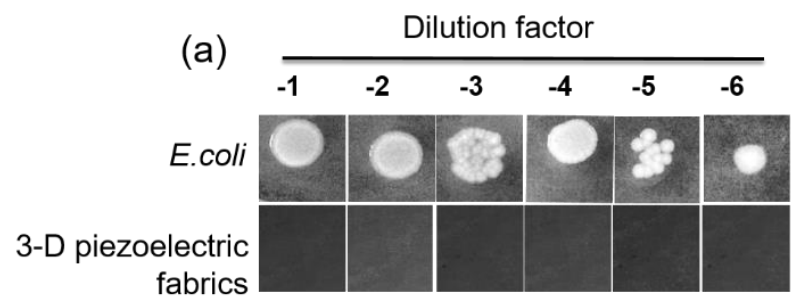

(c)

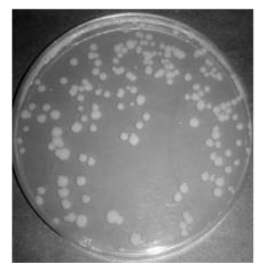

E.coli

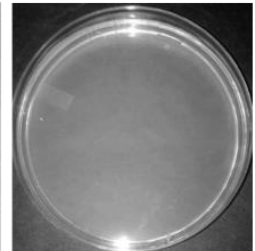

3-D piezoelectric

fabrics
Dilution factor
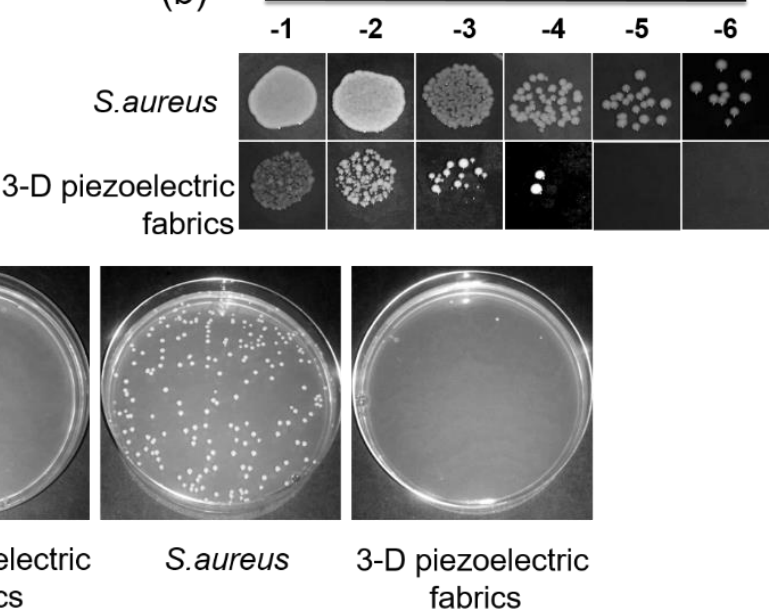

Fig 5. Antibacterial activity of $3-D$ piezoelectric fabrics (a, b) Spot assay analysis showing antibacterial activity of 3-D piezoelectric fabrics against E. coli and S. aureus. After treatment with 3D piezoelectric fabrics $100 \mu \mathrm{l}$ of the culture was 10 -fold serially diluted and $5 \mu 1$ of each of the dilutions was spotted on LB agar plates. E.coli and S. aureus cells, which were not treated with 3-D piezoelectric fabrics, served as control for the experiment (c) Digital micrographs representing antibacterial activity of 3-D piezoelectric fabrics against E. coli and S. aureus. $100 \mu 1$ of E. coli and $S$. aureus cells treated with 3-D piezoelectric fabrics were spread directly on the LB agar plates. Untreated E. coli and S. aureus cells plated on LB agar plates were taken as control. 


\section{References}

[1] M. Li, S. Wang, Z. Zhang and B. Wu, "Effect of Structure on the Mechanical Behaviors of ThreeDimensional Spacer Fabric Composites," Applied Composite Materials, vol 16, no. 1, pp. 1-14, 2009.

[2] K. Großmann, A. Mühl, M. Löser, C. Cherif, G. Hoffmann and A. R. Torun, "New solutions for the manufacturing of spacer preforms for thermoplastic textile-reinforced lightweight structures," Production Engineering, vol 4, no. 6, pp. 589-597, 2010.

[3] A. Mountasir, G. Hoffmann and C. Cherif, "Development of weaving technology for manufacturing three-dimensional spacer fabrics with high-performance yarns for thermoplastic composite applications: An analysis of two-dimensional mechanical properties," Textile Research Journal, vol 81, no. 13, pp. 1354-1366, 2011.

[4] P. G. Ünal, "3D Woven Fabrics," In: Woven Fabrics, Intech Open Access Publication, 2012, pp. 91120.

[5] X. Ye, R. Fangueiro, H. Hu and M. de Araújo, "Application of warp-knitted spacer fabrics in car seats," The Journal of The Textile Institute, vol 98, no. 4, pp. 337-344, 2007.

[6] X. Ye, H. Ho and X. Feng, "Development of the Warp Knitted Spacer Fabrics for Cushion Applications," Journal of Industrial Textiles, vol 34, no. 3, pp. 213-223, 2008.

[7] Y. Liu, H. Hu, H. Long and L. Zhao, "Impact compressive behavior of warp-knitted spacer fabrics for protective applications," Textile Research Journal, vol 82, no. 8, pp. 773-788, 2012.

[8] A. A. Shepherd, "Weft knitted spacer fabrics". USA Patent: US 6779369 B2, 24 August 2004.

[9] T. Dias, R. Monaragala, P. Needham and E. Lay, "Analysis of sound absorption of tuck spacer fabrics to reduce automotive noise," Measurement Science and Technology, vol 18, no. 8, pp. 2657-2666, 2007.

[10] G. B. Delkumburewatte and T. Dias, "Porosity and capillarity of weft knitted spacer structures," Fibers and Polymers, vol 10, no. 2, pp. 226-230, 2009.

[11] Y. Liu and H. Hu, "Compression property and air permeability of weft-knitted spacer fabrics," The Journal of The Textile Institute, vol 102, no. 4, pp. 366-372, 2011.

[12] R. H. Gong, Z. Dong and I. Porat, "Novel Technology for 3D Nonwovens," Textile Research Journal, vol 73, pp. 120-123, 120-123.

[13] R. M. E. S. Fangueiro and H. F. C. Soutinho, "Three-dimensional shaped nonwoven structures for acoustic insulation and production method thereof". USA Patent: US 20130052426 A1, 28 February 2013.

[14] F. Chen, Y. Liu and H. Hu, "An experimental study on vibration isolation performance of weftknitted spacer fabrics," Textile Research Journal, vol 86, no. 20, pp. 2225-2235, 2016. 
[15] S. Pereira, S. C. Anand, S. Rajendran and C. Wood, "A Study of the Structure and Properties of Novel Fabrics for Knee Braces," Journal of Industrial Textiles, vol 36, no. 4, pp. 279-300, 2007.

[16] S. C. Anand and S. Rajendran, "Development of 3D structures for venous leg ulcer management," Third World Conference on 3D Fabrics and Their Applications, Wuhan, 2011.

[17] U. Wollina, M. Heide and M. Swere, "Spacer Fabrics - A Potential Tool in the Prevention of Chronic Wounds," Exogenous Dermatology, vol 1, pp. 276-278, 2002.

[18] U. Wollina, M. Heide, W. Müller-Litz, D. Obenauf and J. Ash, "Functional Textiles in Prevention of Chronic Wounds, Wound Healing and Tissue Engineering," Textiles and the Skin, vol 31, pp. 8297, 2003.

[19] N. Soin, T. H. Shah, S. C. Anand, J. Geng, W. Pornwannachai, P. Mandal, D. Reid, S. Sharma, R. L. Hadimani, D. V. Bayramol and E. Siores, "Novel "3-D spacer" all fibre piezoelectric textiles for energy harvesting applications," Energy \& Environmental Science, vol 7, no. 5, pp. 1670-1679, 2014.

[20] W. Zeng, X.-M. Tao, S. Chen, S. Shang, H. L. W. Chan and S. H. Choy, "Highly durable all-fiber nanogenerator for mechanical energy harvesting," Energy Environ. Sci., vol 6, pp. 2631-2638, 2013.

[21] J. Fang, H. Niu, H. Wang, X. Wang and T. Lin, "Enhanced mechanical energy harvesting using needleless electrospun poly(vinylidene fluoride) nanofibre webs," Energy Environ., vol 6, no. 9, pp. 2196-2202, 2013.

[22] D. V. Bayramol, N. Soin, T. Shah, E. Siores, D. Matsouka and S. Vassiliadis, "Energy Harvesting Smart Textiles," In: Smart Textiles Fundamentals, Design, and Interaction, Springer, 2017, pp. 199-231.

[23] N. Soin, S. C. Anand and T. H. Shah, "Energy Harvesting and Storage Textiles," \%1 içinde Handbook of Technical Textiles: Technical Textile Applications, Woodhead Publishing, 2016, pp. 357-396.

[24] Y. Yang and H. Hu, "Spacer fabric-based exuding wound dressing - Part I: Structural design, fabrication and property evaluation of spacer fabrics," Textile Research Journal, vol 0, no. 00, pp. 1-12, 2016.

[25] B. Crina, M. Blaga, V. Luminita and R. Mishra, "Comfort properties of functional weft knitted spacer fabrics," Tekstil ve Konfeksiyon, vol 23, no. 2, pp. 220-227, 2013.

[26] T. P. Rajan, L. D. Souza, G. Ramakrishnan and G. M. Zakriya, "Comfort properties of functional warp-knitted polyester spacer fabrics for shoe insole applications," Journal of Industrial Textiles, vol 45, no. 6, pp. 1239-1251, 2016.

[27] S. Arabuli, V. Vlasenko, A. Havelka and Z. Kus, "Analysis of Modern Methods for Measuring Vapor Permeability Properties of Textiles," Liberec, 2010.

[28] Z. Stempien, T. Rybicki and E. Rybicki, "In-situ deposition of polyaniline and polypyrrole electroconductive layers on textile surfaces by the reactive ink-jet printing technique," Synthetic 
Metals, vol 202, pp. 49-62, 2015.

[29] V. Arumugam, R. Mishra, J. Militky, L. Davies and S. Slater, "Thermal and water vapor transmission through porous warp knitted 3D spacer fabrics for car upholstery applications," The Journal of The Textile Institute, vol 108, no. 7, pp. 1095-1105, 2017.

[30] P. Gürkan Ünal and M. E. Üreyen, "Mechanical and Permeability Properties of Sportech Fabrics," Industria Textila, vol 67, no. 3, pp. 151-156, 2016.

[31] P. D. Stapleton and P. W. Taylor, "Methicillin resistance in Staphylococcus aureus: mechanisms and modulation," Science Progress, vol 85, no. 1, pp. 57-72, 2002.

[32] S.-H. Kim, H.-S. Lee, D.-S. Ryu, S.-J. Choi and D.-S. Lee, "Antibacterial Activity of Silvernanoparticles Against Staphylococcus aureus and Escherichia coli," Korean Journal of Microbiology and Biotechnology, vol 39, no. 1, pp. 77-85, 2011.

[33] E. D. Cavassin, L. F. P. de Figueiredo, J. P. Otoch, M. M. Seckler, R. A. de Oliveira, F. F. Franco, V. S. Marangoni, V. Zucolotto, A. S. S. Levin and S. F. Costa, "Comparison of methods to detect the in vitro activity of silver nanoparticles (AgNP) against multidrug resistant bacteria," Journal of Nanobiotechnology, vol 13, no. 64, pp. 1-16, 2015.

[34] A. Taglietti, Y. A. D. Fernandez, E. Amato, L. Cucca, G. Dacarro, P. Grisoli, V. Necchi, P. Pallavicini, L. Pasott and M. Patrini, "Antibacterial Activity of Glutathione-Coated Silver Nanoparticles against Gram Positive and Gram Negative Bacteria," Langmuir: the ACS journal of surfaces and colloids, vol 28, no. 21, pp. 8140-8148, 2012.

[35] E. Amato, Y. A. Diaz-Fernandez, A. Taglietti, P. Pallavicini, L. Pasotti, L. Cucca, C. Milanese, P. Grisoli, C. Dacarro, J. M. Fernandez-Hechavarria and V. Necchi, "Synthesis, Characterization and Antibacterial Activity against Gram Positive and Gram Negative Bacteria of Biomimetically Coated Silver Nanoparticles," Langmuir: the ACS journal of surfaces and colloids, vol 27, no. 15, pp. 9165-9173, 2011. 